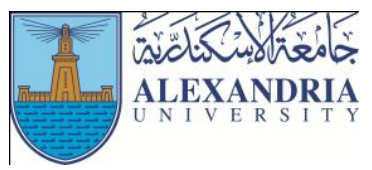

\author{
Journal of Applied Sports Science \\ June 2016, Volume 6, No. 2 \\ www.jass.alexu.edu.eg
}

\title{
The Effect of Recreational Program on Developing Some Psychological Skills and Performance Level for Table Tennis Juniors
}

\author{
Emam Gaber Emam Hassnein ${ }^{1}$, Rana Hosny Amin Othman ${ }^{2}$ \\ ${ }^{1}$ Lecturer in games training department, faculty of physical education, Alexandria University, Egypt \\ ${ }^{2}$ Lecturer in department of recreation, faculty of physical education for girls, Alexandria University, Egypt
}

\begin{abstract}
Scientific development became the main characteristic in all fields of life nowadays; physical education was forced to meet scientific development through new methods and integration between different sciences to reach high levels in the athletic field in general and table tennis in particular. Through the 2 researchers' observation and previous study results and according to their experience in recreation and table tennis and pilot studies results, it was found that training period formation in table tennis in most of clubs training programs, focus is only on physical and skillful aspects as psychological and recreational aspect is ignored, despite of this aspect importance, also this has a positive effect on players, as table tennis is an individual game, this requires the player to enjoy self-confidence, concentration, motivation and other skills enabling him to respond quickly to situations and variables he experiences during match which may, in turn affect skillful performance during match, as recreational activities receive not concern in training period and also some trainers ignore them despite their importance and the importance of developing psychological skills during sports season specially during preparing for their effective role in assisting in winning in match through the players selfconfidence, from here it was focused on the study idea and subject, having recreational program and identifying its effects on developing some psychological skills and its relationship to table tennis juniors performance level.
\end{abstract}

Study introduction and problem:

cientific development became the main characteristic

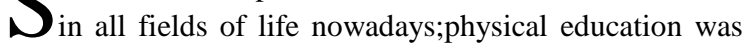
forced to meet scientific development through new methods and integration between different sciences to reach high levels in the athletic field in general and table tennis in particular.

Table tennis is a game subjected to many developments that aims at performance important to entertain spectator and trying to make player use all his potentials to be a good performer and finally develop the game level.

Ismael, Hazem Mohamed (2006) states that table tennis imposed itself as an activity that was considered to be a popular athletic activity in all countries whose citizens practice it as a recreational activity from one side and high levels activities from the other side (10:2).

El Basti ,Ayman, Shawqi Magdi (1999)and Hassanian, Imam Gaber(2000)agree upon that table tennis is favored by all as an attractive game suitable physical and psychologically for all ages and genders and provide its players with multi physical advantages as it develops biosystems, increases flexibility and advances neuromuscular adjustment helps in attention concentration and ability to respond, quick reaction and making rapid decision as required by situation, in addition to its spiritual effect of reactivation and enjoyment of spectators (5:132), (9:2).

Saleh, Sheriff fathi (2003) believes that developing main skills is very important and needs new view the training program in table tennis in general and juniors training program is particular (20:295).

The two researchers believe that table tennis matches relate to many emotional situations as success and failure experiences are clear from one moment to another in the same situation, also the player responds to such situations as a result of training his physical, skillful and psychological skills to achieve the best result in matches especially in the match definite scores.

Gholi, Ismael Al Kora (2001) state that according to what was indicated by the American association of physical health and education and recreation about recreation contribution in communities life, through achieving human needs for self expression and developing the individual's physical, mental and emotional health as well as getting rid of pressures and tensions accompanying 
modern life and availing a personal life full of happiness and stability. (8)

Also, psychological skills programs aims at helping players to improve athletic performance and making athletic practices a method of joy and recreation a natural means for psychological harmony and mental and physical relation due to the positive effects of recreational activities including getting rid of tension, psychological tiredness, anxiety and mental fatigue.

El Hamhamy, Mohamed,Abdel Aziz,Ayda(1998) and Mohamed, Tahani Abdel El Salam (2001) agree that recreational activities provide individuals with new skills, actual mental and psychological abilities and meet physical, psychological physiological and social needs as self apparitions, loyalty and feeling safe and happy (6) (11).

Richard Krwas (2001) adds that participation in recreational activities programs increase self confidence and ability to deal with others and competition in community regardless of age, education, gender or financial status (18:5).

Rateb, Osama Kamel (2000) mentions that many trainers are keen to correct performance errors through more exercise while the real problem may not be due to lack of physical skills, rather lack of psychological skills, when the player precipitates in an athletic competition, he may need more than psychosomatic ability, accordingly the player needs to develop many psychological skills such as recreation (physical, mental) under effects of competition pressures as well as improving attention concentration, self confidence, imagination, achievement, motivation and ability to deal with anxiety (16:77).

Through the 2 researchers' observation and previous study results and according to their experience in recreation and table tennis and pilot studies results, it was found that training period formation in table tennis in most of clubs training programs, focus is only on physical and skillful aspects as psychological and recreational aspect is ignored, despite of this aspect importance, also this has a positive effect on players, as table tennis is an individual game, this requires the player to enjoy self confidence, concentration, motivation and other skills enabling him to respond quickly to situations and variables he experiences during match which may, in turn affect skillful performance during match, as recreational activities receive not concern in training period and also some trainers ignore them despite their importance and the importance of developing psychological skills during sports season specially during preparing for their effective role in assisting in winning in match through the players self confidence, from here it was focused on the study idea and subject, having recreational program and identifying its effects on developing some psychological skills and its relationship to table tennis juniors performance level.

\section{Study objectives:}

The study aims at compiling a recreational program and identifying its effects on:

1- Developing some psychological skills for table tennis juniors under 17 years.

2- Developing performance level for table tennis juniors under 17 years.

\section{Study hypotheses:}

1- The recreational program has a positive effect on developing some psychological skills for table tennis juniors under 17 years.

2- The recreational program has a positive effect on developing performance level for table tennis juniors under 17 years.

\section{Study terminology:}

\section{Recreational program (pragmatic definition)}

Some of regular recreational activities supervised by a recreational pioneer for developing some psychological skills and performance level of table tennis juniors.

\section{Psychological skills:}

Allawi, Mohamed Hassan (2006) states that it is an individual's proficiency to employ and use his mental and emotional abilities through training situations and athletic competitions to achieve the desired dynamic objectives. (3:159)

\section{Study procedures:}

\section{Study method:}

The 2 researchers used the experimental method of experimental design of one group through (pre-post) test as suitable for the study nature.

\section{Study scopes:}

- Time scope: the study was made from 21/07/2012 to 20/10/2012 for 3 months during the period of preparing for the training season. 
- Palatial scope: table tennis hall in Alexandria sporting club.

- Human scope: juniors of table tennis under 17 years, Alexandria sporting club.

\section{Study community and sample:}

The study sample was selected deliberately 12 juniors from table tennis players, Alexandria sporting club under 17 years and three were set aside due to failing to attend training regularly, the researchers selected this sample due to the following:
1- Most of the clubs juniors attend training regularly.

2- One of the excellent series clubs in table tennis.

3- The club's management agreement on making the research.

\section{The main study sample consistency:}

The researcher verified the main study sample consistency in the following anthropometric variables:

- Consistency of group under 17 years in age, height and weight was verified

Table (1)

Consistency of the study sample in anthropometric variables (under 17 years)

\begin{tabular}{|c|c|c|c|}
\hline \multirow{2}{*}{ Variables } & \multicolumn{2}{|c|}{ Statistical treatment N=12 } \\
\cline { 2 - 4 } & Arithmetic mean & Standard deviation & -0.152 \\
\hline Age & 15.708 & 0.45 & 0.2177 \\
\hline Height & 159.17 & 1.528 & 0.196 \\
\hline Weight & 52.167 & 1.6 & Torsion coefficient \\
\hline
\end{tabular}

Also the researchers verified the consistency of the basic applying the program. study sample in psychological and basic skills before

Table (2)

Consistency of the main study sample in pretest for testing psychological skills (less than 17 years)

\begin{tabular}{|c|c|c|c|}
\hline \multirow{2}{*}{ Variables } & \multicolumn{2}{|c|}{ Statistical treatment N=12 } \\
\cline { 2 - 4 } & Arithmetic mean & Standard deviation & 0.2623 \\
\hline Scenario & 12.833 & 0.718 & -0.262 \\
\hline Relaxation & 11.167 & 0.718 & 0.0862 \\
\hline Attention & 10.917 & 0.669 & 0.2623 \\
\hline Anxiety & 8.8333 & 0.718 & -0.478 \\
\hline Self confidence & 9.25 & 0.754 & 1.0679 \\
\hline achievement & 6.5 & 0.674 & \\
\hline
\end{tabular}

Table (3)

Consistency of the main study sample in pretest for testing basic skills (less than 17 years)

\begin{tabular}{|c|c|c|c|}
\hline \multirow{2}{*}{ Variables } & \multicolumn{2}{|c|}{ Statistical treatment N=12 } \\
\cline { 2 - 4 } & Arithmetic mean & Standard deviation & Torsion coefficient \\
\hline Serving & 30 & 1.954 & 0.088 \\
\hline Smashing strike & 19.333 & 1.073 & 0.255 \\
\hline Frontal straight strike & 18.083 & 1.379 & -0.426 \\
\hline Back push & 39.833 & 1.467 & 0.9641 \\
\hline Frontal interruption & 14 & 1.348 & 0.016 \\
\hline Frontal suppression & 13.75 & 1.357 & 0.2784 \\
\hline
\end{tabular}

It is clear from tables (1.2.3) that data torsion coefficient ranged between $+3,-3$ to confirm consistency of all variables for whole group and that data are characterized by moderation and non dispersion.

\section{Data collection tools:}

The researchers used many methods for collecting data of this research in conformity with its nature and data required to be obtained as follows:

1- Referential survey of scientific literature related to the research nature. 
2- The researchers carried out some tests and measurements which included some primary measurements and skillful tests, attachment No. (2) as follows:

- Age, height, weight.

- Testing frontal serving, lateral rotation.

- Testing speed measurement and accuracy smash strike by the frontal bat side.

- Testing speed measurement and accuracy of straight strike by the frontal bat side to respond to the straight strike.

- Testing divided table.

- Testing speed measurement and accuracy of ball interruption skill by the bat frontal side to respond to spiral strike.

- Testing speed measurement and accuracy of ball suppression skill by the bat frontal side to respond to spiral strike.

- Testing psychological skills for Mohamed Hassan Allawi after amend attachment No. (3)

\section{Psychological skills test:}

The researchers identified psychological skills through some scientific references (21) (1) (16) (17), and they were submitted to experts attachment No. (1)to identify the most important psychological skills of table tennis juniors and the two researchers found that $70 \%$ agreement for skills selection, also some psychological skills were combined in one skill according to the opinion of some experts as follows:

1- Achievement motivation (assiduity, achievement motivation, achievement need).

2- Self confidence (self confidence, confidence in others).

3- Relaxation ability (physical relaxation ability, mental relaxation ability, tension control).

4- Mental imagination

5- Dealing with anxiety ability

6- Concentration and attention control

Accordingly, 6 skills similar to psychological skills by testing psychological skills translated and amended by Mohamed Allawi, a scale suitable for the studied age group.

\section{Test description:}

Mental skills test translated to Arabic by Mohamed Hassan Allawi (1998) to measure some important psychological aspects of athletic performance:

1- Achievement motivation.

2- Self confidence.

3- Relaxation ability.

4- Mental imagination ability.

5- Dealing with anxiety ability.

6- Attention concentration ability.

The test includes 24 sentences and every dimension of the 6 is represented by four sentences and the junior answers the tests sentences on a six filed scale (1:543-547).

\section{Recreational program suggested for table tennis: attachment No. (4)}

\section{Steps of recreational program design:}

\section{Identifying the program objective:}

The program aims at developing some psychological skills and performance level for table tennis juniors under 17 years.

\section{Program content identification:}

The researcher explored experts' opinions to identify suitable recreational activities to achieve the suggested recreational program objective.

\section{Identifying the program time plan:}

The time plan was identified as follows: (3) months, (24) units, 2 units/week, each unit's time (45) minute, (5) minutes for preparation, (25) minute as a main part, (15) minutes for the final part.

\section{First explorative study:}

The researcher made a statistical analysis for some matches of juniors to identify the most used skills, and it was agreed upon the most common and used skills, more than $90 \%$ as follows:

Frontal serving, lateral rotation, frontal smashing strike, frontal straight strike, frontal pushing strike, frontal interruption strike, frontal suppression.

\section{Second explorative study:}

The researchers made an explorative study to identify the whole study community for selecting the sample and 
identifying the study sample training periods, the most important results of selecting Alexandria sporting club to apply the research, the suitable time for recreational activity practice was the period of preparation in the athletic season.

\section{Basic study:}

The researchers applied the suggested recreational program from 21/07/2012 to 20/10/2012 for (3) months on the study sample.

\section{Statistical treatments:}

The researchers used statistical treatments suitable for the study sample:

1- Arithmetic mean

2- Standard deviation

3- Torsion coefficient

4- (T) test

5- Improvement percentage

Discussing results:

Table (4)

Arithmetic mean, standard deviation and $\mathrm{T}$ value differences between pre and post test for psychological and skillful tests for the experimental research sample

\begin{tabular}{|c|c|c|c|c|c|c|c|}
\hline \multirow{3}{*}{ Research variables } & \multicolumn{4}{|c|}{$\mathrm{N}=12$} & \multirow{3}{*}{ Arithmetic mean for differences } & \multirow{3}{*}{ Standard deviation for differences } & \multirow{3}{*}{ (T) test } \\
\hline & \multicolumn{2}{|c|}{ Pre test } & \multicolumn{2}{|c|}{ Post test } & & & \\
\hline & S1 & R1+- & S2 & $\mathrm{R} 2+-$ & & & \\
\hline Scenario & 12.833 & 0.718 & 15.333 & 0.888 & 2.5 & 1.382 & $* * 6.268$ \\
\hline Relaxation & 11.17 & 0.72 & 11.42 & 1.311 & 0.25 & 0.75 & 1.15 \\
\hline Attention & 10.917 & 0.669 & 14.833 & 1.267 & 3.917 & 0.793 & $* * 17.11$ \\
\hline Anxiety & 8.8333 & 0.718 & 14.853 & 1.505 & 5.75 & 0.965 & $* * 20.63$ \\
\hline Self confidence & 9.25 & 0.754 & 14.75 & 1.215 & 5.5 & 1 & $* * 19.05$ \\
\hline Achievement & 6.5 & 0.674 & 6.6667 & 1.073 & 0.17 & 0.72 & 0.8 \\
\hline Serving & 30 & 1.954 & 36.75 & 1.765 & 6.75 & 0.965 & $* * 24.22$ \\
\hline Smashing strike & 19.333 & 1.073 & 22.5 & 1.446 & 3.167 & 1.267 & $* * 8.656$ \\
\hline Frontal straight & 18.083 & 1.379 & 22.833 & 1.193 & 4.75 & 1.288 & $* * 12.77$ \\
\hline Back push & 39.833 & 1.467 & 44.5 & 2.023 & 4.667 & 1.826 & $* * 8.854$ \\
\hline Frontal interruption & 14 & 1.348 & 17.667 & 1.303 & 3.667 & 1.557 & $* * 8.158$ \\
\hline Frontal suppression & 13.75 & 1.357 & 18.417 & 1.564 & 4.667 & 1.614 & $* * 10.01$ \\
\hline
\end{tabular}

It is clear from table (4) that there are statistical significant differences between pre and post test as (T) value calculated for psychological skills reached, imagination (6.268), attention (17.11), anxiety (20.63), self confidence (19.05), these values are higher than $(\mathrm{T})$ tabular values at level (0.05) this development proves the excellence of the recreational program applied to experimental group, there was improvement in skills of relaxation, and achievement motive even is not statistically significant.

The researchers attribute this results to mental imagination increase positively correlated to increase in self confidence, attention concentration and dealing with anxiety as Rushall (1991) and Noless (2002) state that mental imagination may contribute in increasing readiness for performance, positive thinking and increase individual's ability to attention concentration specially before competition (19:87), (14:84)
Nurray (1995), Plessinger (1999), Rateb, Ossma Kamel (2000), Shamoun, Mohamed El Araby (2000) and Allawi, Mohamed Hassan (2002) confirm the importance of mental imagination in the athletic field as it contributes in improving level of self confidence, positive thinking and controlling level of watchfulness and athletic competition anxiety control. (12:83), (15:85), (16:11), (21:41), (2:48)

The researchers believe that mental imagination is very important in table tennis due to recovering all previous experiences to achieve the required objective, confirming this experience, removing negative thoughts, supporting self confidence and increasing performance motives and achieving objectives.

All these results agree with what was mentioned by Fawzi, Ahmed Amin (2003)and Zahran, Hamid Abdelsalam(2005)that mental abilities of this stage juniors may grow quickly but intelligence grows slowly till the 
end of this stage in addition to an increase in the ability of maintaining information, dynamic pictures and ability to recall them with neither increase nor decrease, the junior will be concentrating in one subject to give it his all time and effect, and his ability to skilful and planning understanding will increase (17:3), (22:28).

The researchers refer this result to the suggested recreational program ability to enhance juniors self confidence, accordingly their ability to deal with anxiety and attention concentration increased which is supported by what was mentioned by Rateb, Ossama Kamel (2001) and Zahran, Hamid Abdel Salam (2005) that negligence and non care of juniors in this stage may expose him to depression, hopeless and afraid from some situation, accordingly the junior's self confidence shall be enhanced as at the end of this stage, he may feel anxious. (17:67), (22:387-397)

Accordingly, the first hypothesis of the study was verified, the recreational program has a positive effect on developing some psychological skills for table tennis juniors under 17 years.

Also from the same table it is clear that there are statistical significant differences between pre and post tests as $\mathrm{T}$ value calculated for table tennis skills were serving $(24,22)$ frontal smashing strike $(8,656)$, frontal straight strike $(12,77)$, back push $(8,854)$, frontal interruption $(8,158)$, frontal suppression $(10,01)$, these values are higher than $(\mathrm{T})$ tabular values at level (0.05).

The researchers attributed this improving in performance level to improving in some psychological skills affecting table tennis skills level, as player's self confidence and ability to concentration, imagination and dealing with anxiety enable him to good performance.

ElDin, Tarek Bader (2013) confirms that imagination may help the junior to perform some psychological skills such as self confidence, and positive thinking, also this skill is the most important psychological skill to learn and develop the remaining skills, as dynamic imagination in athletic competition may help the player in mental preparation and reducing tension and anxiety degree and reaching the highest level in athletic competition. (4:55, 56)

Results of study of Nadim, Heba Mohamed (2008) confirms that training and developing psychological skills may reduce anxiety level and increase self confidence and in turn, developing performance level. (13)

Accordingly, the study second hypothesis was verified, recreational program has a positive effect on developing performance level of table tennis juniors under 17 years.

Table (5)

Value and percentages of improving between pre and post test for the researched psychological and skilful tests

\begin{tabular}{|c|c|c|}
\hline \multirow{2}{*}{ Research variables } & \multicolumn{2}{|c|}{$\mathrm{N}=12$} \\
\cline { 2 - 3 } & Improving rate & Improving percentage\% \\
\hline Scenario & 2.5 & 2.238 \\
\hline Relaxation & 0.25 & 35.88 \\
\hline Attention & 3.917 & 65.09 \\
\hline Anxiety & 5.75 & 59.46 \\
\hline Self confidence & 5.5 & 2.654 \\
\hline Achievement & 0.17 & 22.5 \\
\hline Serving & 6.75 & 16.38 \\
\hline Smashing strike & 3.167 & 26.27 \\
\hline Frontal straight & 4.75 & 11.72 \\
\hline Back push & 4.667 & 26.19 \\
\hline Frontal interruption & 3.667 & 33.94 \\
\hline Frontal suppression & 4.667 & \\
\hline
\end{tabular}

From table (5) it is clear that there are improving percentages in psychological skills and performance level for table tennis juniors under 17 years between pre and post test, although skills of relaxation and achievement motivation improved slightly, the researchers attribute improving in psychological skills and performance level for table tennis juniors under 17 years to the suggested recreational program applied to the research sample.

\section{Conclusions}

1- The suggested recreational program resulted in developing some psychological skills for table tennis juniors under 17 years.

2- The suggested recreational program developed skilful performance level for table tennis juniors under 17 years. 
3- Significant improvement in skills of ability to imagine, attention concentration, ability to deal with anxiety, self confidence for table tennis under 17 years.

\section{Recommendations}

1- Using the suggested recreational program in the program of table tennis juniors' psychological preparation.

2- Making similar studies on other ages and girls teams in table tennis.

3- Using recreational programs for developing other skills for table tennis juniors.

\section{References}

1- Allawi , Mohamed Hassan (1998): psychological tests encyclopedia, book center for publishing, Cairo.

2(2002): psychology and athletic competition, Dar El Fikr Al Arabi, Cairo.

3- ___ (2006): approach to athletic psychology book center for publishing, fifth edition, Cairo.

4- Badr ElDin ,Tarek Mohamed (2013): psychological care for athletic junior, Dar Al Wafa, first edition, Cairo.

5- El Basti, Ayman AbdelFattah, Shawqi, Magdi Ahmed (1999): Kinematic characteristics of striking arm in the frontal smashing strike as an educational basis for table tennis juniors, published research, theories and applications, scientific managing issue No 36, faculty of physical education for boys, Alexandria University.

6- El Hamahamy, Mohamed, Moustafa Ayda AbelAziz (1998): recreation between theory and practice, book center for publishing, second edition Cairo.

7- Fawzi, Ahmed Amin (2003): psychology fundamentals, concepts- applications, Dar El Fikr El Arabi, first edition, Cairo.

8- Gholi, Ismael El Kora, Ibrahim, Marwan Abelmeguid (2001): recreational education and spare times, Al Warak for publishing and distribution, Jordan

9- Hassanian, Emam Gaber Emam (2000): applied program suggested for developing attention concentration and its effect on speed and accuracy of performance of table tennis for some main attacking and defensive principals, un published master theses, faculty of physical education for boys, Alexandria University.

10- Ismael , Hazem Mohamed (2006): relationship of some skills to matches results in table tennis, un published master thesis, Egypt, faculty of physical education for boys, Banha University, Egypt.

11- Mohamed, Tahani AbelSalam (2001): recreation and recreational education, Dar El Fikr Al Arabi, Alexandria.

12- Murray, J (1995): Attention al Control inten nis.

13- Nadim, Heba Mohamed (2008): effects of mental training on reducing competition anxiety and effectiveness of skilful performance for Taekwondo players, un published master theses, faculty of physical education for girls, Alexandria University.

14- Noless (2002): Visualization and mental imagery.

15- Plessinger A (1999): The effect of mental imagery on Athletic performance. http//www.vanderbilt.edu/ans/psychology/heath psychology/mental imagery.htm

16- Rateb, Ossama Kamel (2000): physical education psychological between theory and practice, Dar El Fikr El Arabi, second edition, Cairo.

$17-$ (2001): juniors' psychological preparation, Dar El Fikr El Arabi, Cairo.

18- Richard , Kraws (2001): Recreation and Leisure in society, Temple University, James \& Barlette.

19- Rushall, B, (1991): Psyching in sport, London, Pelham.

20- Saleh ,Sherif Fathi (2003): effect of a training program by using different heights table on level of performing some attacking skills for table tennis juniors, third edition, scientific magazine of physical education, Tanta University, Egypt.

21- Shamoun, Mohamed El Arabi (2000): mental training in the athletic field, Dar El Fikr Al Arabi, second edition, Cairo.

22- Zahran , Hamid Abdel Salam (2005): growth psychology- childhood and adolescence- sixth edition, book world, Cairo. 